\title{
Diverse molecular functions of aspartate $\beta$-hydroxylase in cancer (Review)
}

\author{
WENQIAN ZHENG ${ }^{1,2}$, XIAOWEI WANG ${ }^{1}$, JINHUI HU ${ }^{1,2}$, BINGJUN BAI $^{1,2}$ and HONGBO ZHU ${ }^{1,2}$ \\ ${ }^{1}$ Department of Colorectal Surgery, Sir Run Run Shaw Hospital, School of Medicine, Zhejiang University; \\ ${ }^{2}$ Key Laboratory of Biotherapy of Zhejiang Province, Sir Run Shaw Hospital, Hangzhou, Zhejiang 310016, P.R. China
}

Received July 14, 2020; Accepted September 11, 2020

DOI: $10.3892 /$ or.2020.7792

\begin{abstract}
Aspartate/asparagine $\beta$-hydroxylase $(\mathrm{AspH})$ is a type II transmembrane protein that catalyzes the post-translational hydroxylation of definite aspartyl and asparaginyl residues in epidermal growth factor-like domains of substrates. In the last few decades, accumulating evidence has indicated that AspH expression is upregulated in numerous types of human malignant cancer and is associated with poor survival and prognosis. The AspH protein aggregates on the surface of tumor cells, which contributes to inducing tumor cell migration, infiltration and metastasis. However, small-molecule inhibitors targeting hydroxylase activity can markedly block these processes, both in vitro and in vivo. Immunization of tumor-bearing mice with a phage vaccine fused with the $\mathrm{AspH}$ protein can substantially delay tumor growth and progression. Additionally, AspH antigen-specific $\mathrm{CD}^{+}{ }^{+}$and $\mathrm{CD}^{+} \mathrm{T}$ cells were identified in the spleen of tumor-bearing mice. Therefore, these agents may be used as novel strategies for cancer treatment. The present review summarizes the current progress on the underlying mechanisms of $\mathrm{AspH}$ expression in cancer development.
\end{abstract}

\section{Contents}

1. Introduction

2. Molecular functions of AspH in cancer

3. AspH expression in various types of cancer

4. Conclusion and outlook

Correspondence to: Professor Hongbo Zhu, Department of Colorectal Surgery, Sir Run Run Shaw Hospital, School of Medicine, Zhejiang University, 3 Qingchun East Road, Hangzhou, Zhejiang 310016, P.R. China

E-mail: ykzhb@zju.edu.cn

Key words: aspartate $\beta$-hydroxylase, tumor, small-molecule inhibitors, Notch pathway, PI3K pathway, immunotherapy

\section{Introduction}

Human aspartate/asparagine $\beta$-hydroxylase $(\mathrm{AspH})$ is a highly conserved enzyme that is widely expressed in proliferating placenta trophoblastic cells and is almost undetectable in normal adult tissues (1). AspH is an $\sim 86 \mathrm{kDa}$ type II transmembrane protein located on the luminal side of the endoplasmic reticulum (ER) that hydroxylates $\beta$-carbons of specific aspartyl and asparaginyl residues in consensus sequences of epidermal growth factor-like domains (EGFDs) of target proteins in the presence of ferrous iron (2-6). In contrast to the canonical EGFD disulfide pattern, AspH catalyzes noncanonical EGFD substrates (Cys 1-2, 3-4, 5-6) (7). AspH, which is located at position q12.1 of human chromosome 8 , is a member of the $\alpha$-ketoglutarate (also known as 2-oxoglutarate, 2-OG)-dependent dioxygenase family of prolyl and lysyl hydroxylases, which serve a vital role in collagen biosynthesis (8-10). Via alternative splicing and exon sharing, the gene encodes four functionally distinct proteins: AspH, humbug, junctin and junctate $(3,10)$. Humbug serves a role in calcium homeostasis and belongs to the N-terminal fragment that completely lacks the catalytic activity of $\mathrm{AspH}(3,11)$. In contrast, the $\mathrm{COOH}$-terminal region of $\mathrm{AspH}$ contains the hydroxylase catalytic domain, which includes dibasic glycine and His 2 motifs that are essential for catalytic activity (3). The 26-kDa calsequestrin binding protein junctin and transcript junctate are involved in regulating intracellular transient calcium release from the sarcoplasmic reticulum in cardiac and skeletal muscle $(3,10,12,13)$.

Mutations in the $\mathrm{AspH}$ gene can have consequences in lens instability (14). Traboulsi syndrome is an extremely rare ophthalmological disorder that is caused by homozygous variants in the $\mathrm{AspH}$ gene, wherein facial dysmorphism, lens dislocation, anterior segment abnormalities, and spontaneous filtering blebs are observed (15-17). Loss of murine hydroxylase activity is associated with increased intestinal tumor incidence and developmental defects similar to those caused by altered Notch signaling (18). In comparison with villous cytotrophoblasts (CTB), extravillous CTB demonstrated stronger AspH immunoreactivity, which led to the clinical condition of impaired embryo implantation (19), suggesting that AspH may serve a role in cell migration and invasion. Additionally, AspH expression is upregulated in breast carcinoma, hepatic carcinoma, cervical cancer and ovarian cancer (20). The AspH 
protein is transferred from the endoplasmic reticulum (ER) membrane to the cell surface, which contributes to enhancing cell migration $(21,22)$. Furthermore, the malignant phenotypes of hepatocellular carcinoma were significantly reversed using a selective small-molecule inhibitor (SMI), MO-I-1100, of AspH targeting $\beta$-hydroxylase activity (23). These observations suggest that AspH may become a potential biomarker for cancer diagnosis and prognosis.

\section{Molecular functions of AspH in cancer}

AspH promotes cancer development and metastasis by activating the Notch signaling pathway. The 2-OG-dependent dioxygenase $\mathrm{AspH}$ hydroxylates aspartate and asparagine residues in certain EGFDs of its substrates, in particular Notch homologues or Notch ligand homologues $(4,6,18)$. The Notch signaling cascade is a highly conserved pathway that affects cell differentiation, proliferation and apoptosis by mediating cell-cell communication, which is essential for human growth and development $(24,25)$. Mammals have four Notch receptors (Notch1-4) and two ligands [Delta-like and Jagged (JAG)] (26). Both the Notch ligands and the extracellular domain (ECD) of Notch receptors contain tandem EGF-like repeats (27-29). Under the condition of $\beta$-hydroxylase activity, AspH binding ligands and receptors in a ligand-dependent manner enhances the stability and interaction between Notch receptors and ligands, leading to conformational changes in Notch $(26,30,31)$. This process makes Notch more sensitive to continuous cleavage by a disintegrin and metalloproteinase (ADAM; S2 cleavage) and by the multiprotein $\gamma$-secretase complex (S3 cleavage) (26). On the other hand, AspH promotes the cleavage of the $\gamma$-secretase complex by directly interacting with ADAM10/17, releasing the Notch intracellular domain, which enters the nucleus and recruits coactivator proteins from the mastermind-like 1 (MAML1) family, forming a Notch transcription activation complex with recombination signal binding protein $\mathrm{J}_{\kappa}(\mathrm{RBPJ})$, also known as CSL [CBF1-Su(H)-LAG1] $(26,29)$. Subsequently, downstream Notch-responsive genes are activated, including hairy and enhancer of split-1 (HES1), hairy-related transcription factor-1 (HEY1), CD44, epithelial cell adhesion molecule, c-Myc, MMP2/9, cyclin D3 and proliferating cell nuclear antigen (Fig. 1) $(29,32)$. It has been demonstrated that the Notch signaling pathway serves a role in regulating exosomes, which are transferred from mesenchymal cells to tumors to promote metastasis $(33,34)$. The activation of the AspH-Notch axis induces MMP/ADAM-mediated exosomal synthesis and release, and the latter markedly enhances breast cancer cell extracellular matrix (ECM) degradation/remodeling, infiltration and metastasis (both in vitro and in vivo) (32). In addition, the structural and functional abnormalities of tumor blood vessels, combined with diffusion deterioration, lead to decreased oxygen levels in regions within solid tumors and induce the expression of stress response proteins, such as hypoxia-inducible factor-1 $\alpha(\mathrm{HIF}-1 \alpha)$ (35). Chen et al (36) demonstrated that HIF-1 $\alpha$ activates Notch signaling by synergizing with the Notch coactivator MAML1 and subsequently increases both HES1 and HEY1 expression levels under hypoxia. In addition, as the upstream target gene of $\mathrm{AspH}$, HIF-1 $\alpha$ enters the nucleus and controls AspH expression at the transcriptional level (37). Upregulated AspH expression stimulates the translocation of Notch to the nucleus by binding to Notch ligands and receptors, consequently governing downstream target genes that mediate cell adhesion, including E-cadherin and tenascin $\mathrm{C}(30,36-38)$. This novel molecular mechanism for HIF-1 $\alpha$-AspH-Notch signaling may serve an important role in cancer invasion and metastasis (Fig. 1).

AspH function in MAPK and PI3K signaling pathways. Several studies have indicated that the MAPK and PI3K signaling pathways are the most general events in various types of human cancer $(39,40)$. The abnormal activation of these proteins affects numerous biological processes, including cell proliferation, differentiation, growth, survival, motility and metabolism (39-41). It has been demonstrated that insulin and insulin-like growth factor (IGF-1) stimulate the intrinsic tyrosine kinase activity of the IGF-1 receptor, subsequently activating the PI3K and MAPK signaling pathways and causing the expression of downstream target substrates, including AKT and ERK (42-44). de la Monte et al (45) reported that insulin and IGF-1 induce the phosphorylation and activation of the PI3K and MAPK cascades, which stimulate $\mathrm{AspH}$ expression and enhance cell motility in hepatocellular carcinoma. Furthermore, GSK3 $\beta$, which is downstream of both the PI3K and MAPK signaling pathways, is phosphorylated (inhibition) at Ser9 by its upstream kinases AKT and p38 (46). However, high levels of AspH lead to decreased GSK3 $\beta$ phosphorylation, which delays tumor cell senescence and promotes tumor progression by interfering with the communication between GSK3 $\beta$ and upstream kinases (Fig. 2A) (47).

AspH may be used as a novel immunotherapy target. Compared with surgery, radiation and chemotherapy, immunotherapy has provided important benefits to patients with melanoma (48). The purpose of cancer immunotherapy is to promote tumor-specific T-cell responses. In the presence of major histocompatibility and CD28 co-stimulation, the T-cell receptor interacts with antigens to activate $\mathrm{T}$ cells, which migrate to tumors, upregulate the expression levels of immune checkpoints, such as cytotoxic T lymphocyte antigen 4 (CTLA-4) and programmed cell death 1 , and produce cytokines such as IFN- $\gamma$, which leads to the expression of programmed cell death ligand 1 (PD-L1) on tumor cells (48). CTLA-4 and PD-L1 are negative regulators that inhibit $\mathrm{T}$-cell activation and induce tumor cell immune escape $(49,50)$. Therefore, numerous efforts have been devoted to the development of inhibitors targeting immune checkpoints, including ipilimumab and nivolumab; these antibodies promote antitumor $\mathrm{CD}^{+}$cytotoxic $\mathrm{T}$ lymphocyte (CTL) responses in patients with melanoma (51). In addition, $\mathrm{CD} 4^{+} \mathrm{T}$ cells promote both the effector and the memory functions of CTLs and enhance their antitumor responses (51). The AspH protein is exposed to the extracellular environment of tumor cells and can be recognized and attacked by the host immune system (52). AspH contains both HLA class I- and class II-limited epitopes, which stimulate AspH antigen-specific $\mathrm{CD}^{+}$and $\mathrm{CD}^{+} \mathrm{T}$-cell responses in human and animal models to elicit antitumor effects (Fig. 3) (52). $\lambda$ phage nanoparticles expressing human AspH-derived proteins and $\mathrm{AspH}$ protein-loaded dendritic cells (DCs) migrate from 


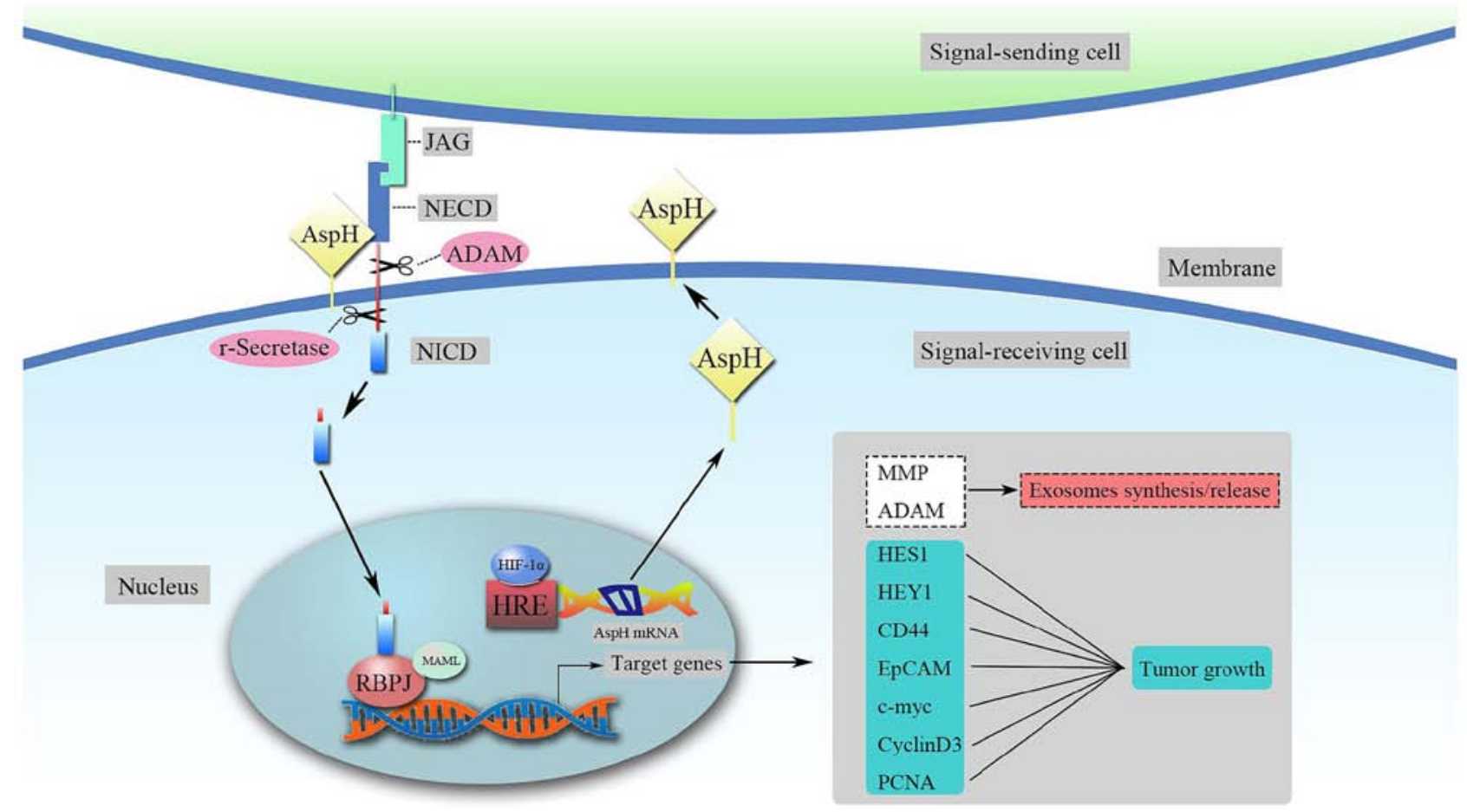

Figure 1. Upregulated AspH activates the Notch signaling pathway. HIF-1 $\alpha$ controls AspH expression at the transcriptional level by interacting with the HRE. AspH upregulation promotes the release of the NICD from the Notch receptor. NICD enters the nucleus and forms a Notch transcription activation complex with RBPJ and MAML. Subsequently, the downstream Notch-responsive genes are activated. AspH, aspartate $\beta$-hydroxylase; NICD, Notch intracellular domain; NECD, Notch extracellular domain; HRE, hypoxia response element; HIF-1 $\alpha$, hypoxia-inducible factor 1 $\alpha$; MAML, mastermind-like; ADAM, a disintegrin and metalloproteinase; HES1, hairy and enhancer of split-1; HEY1, hairy-related transcription factor-1; EpCAM, epithelial cell adhesion molecule; PCNA, proliferating cell nuclear antigen; JAG, Jagged; RBJP, recombination signal binding protein J $\kappa$; ADAM, a disintegrin and metalloproteinase.
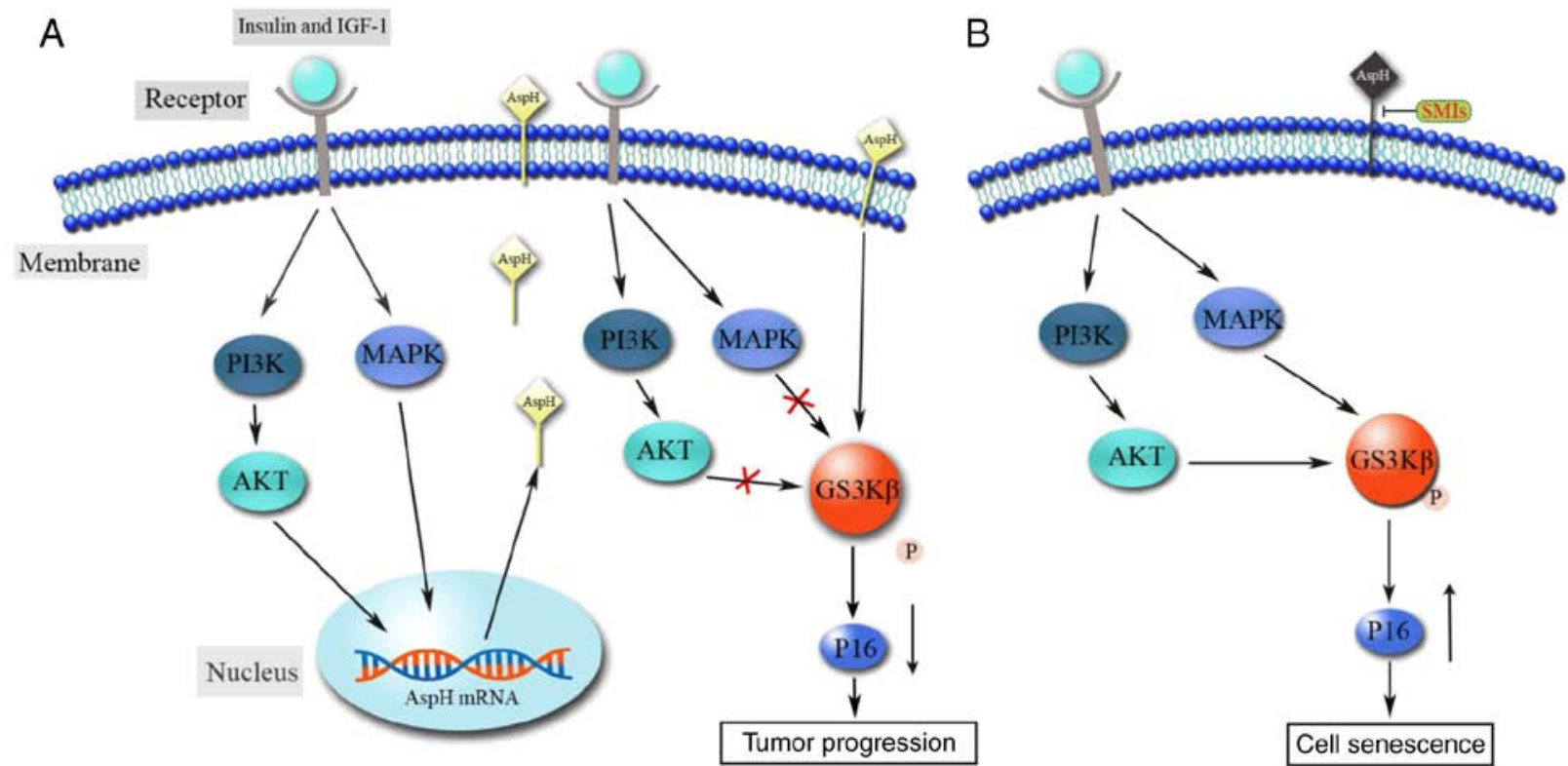

Figure 2. Molecular interpretation of AspH in MAPK and PI3K signaling pathways. (A) Insulin- and IGF-1-stimulated AspH expression is mediated by signals transmitted through MAPK and PI3K. The AspH protein in turn inhibits the phosphorylation of downstream GSK3 $\beta$, which contributes to tumor progression. (B) Inhibitory effect of AspH on GSK3 $\beta$ phosphorylation can be reversed using SMIs targeting AspH hydroxylase activity. AspH, aspartate $\beta$-hydroxylase; SMI, small-molecule inhibitor; IGF-1, insulin-like growth factor 1.

the blood to lymph nodes to activate antigen specific $\mathrm{CD} 4^{+}$and $\mathrm{CD}^{+} \mathrm{T}$ cells; subsequently, $\mathrm{T}$ helper $(\mathrm{Th}) 1$ and $\mathrm{Th} 2$ immune responses are induced to promote lymphocytic infiltration and widespread necrosis in tumors $(52,53)$.

\section{AspH expression in various types of cancer}

AspH in hepatocellular carcinoma (HCC). HCC is the primary hepatic malignancy, with the highest incidence $(\sim 75 \%)$ among 


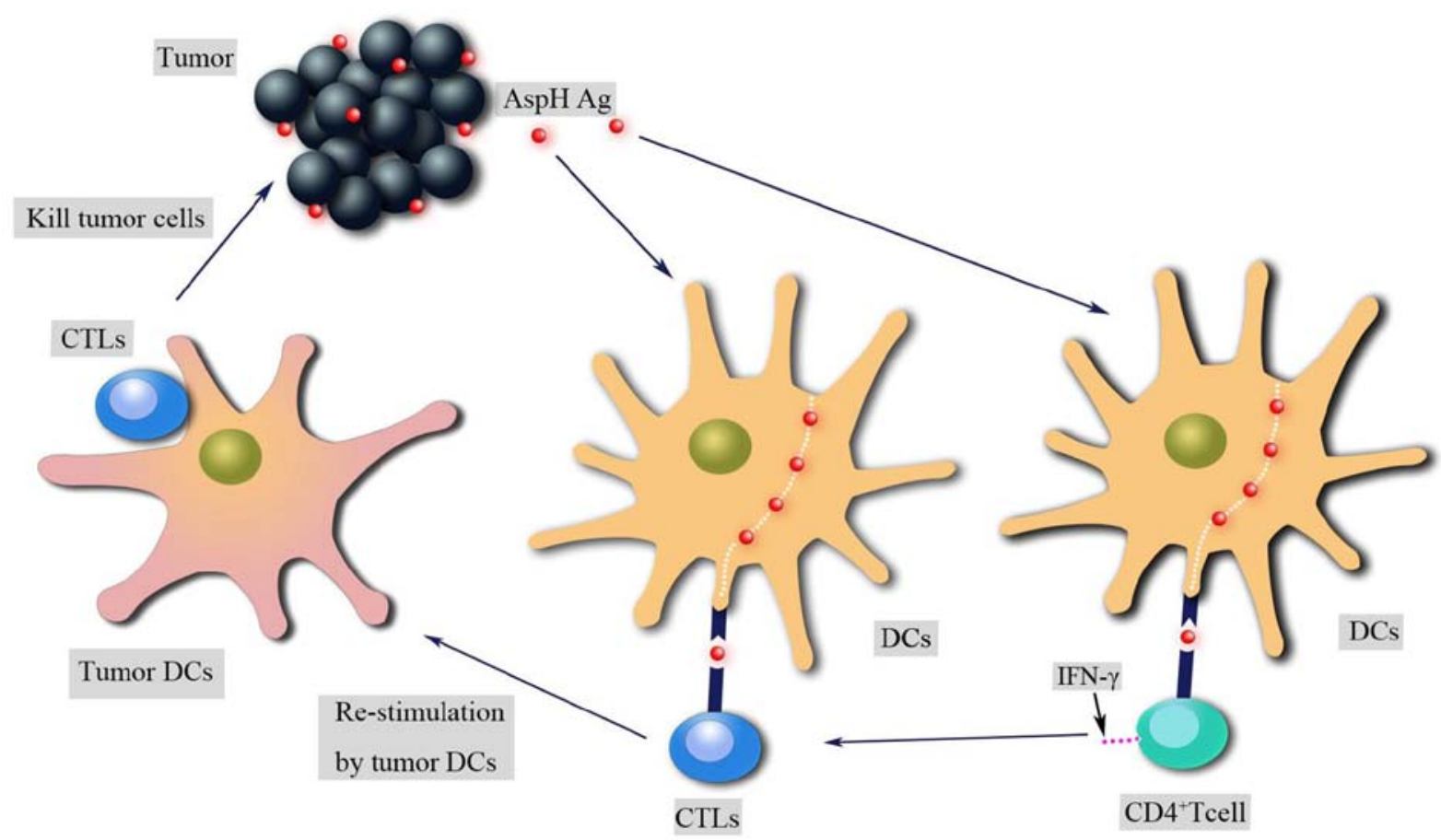

Figure 3. Functions of AspH in the immune system. AspH-specific antigens are taken up by antigen-presenting cells (such as DCs) and migrate from the tumor to draining lymph nodes. During this period, AspH antigens are processed into small peptides, which are then presented on the surface of DCs to stimulate specific $\mathrm{CD} 4^{+} \mathrm{T}$-cell and CTL responses. In addition, $\mathrm{CD} 4^{+} \mathrm{T}$ cells can stimulate CTL activation by secreting IFN- $\gamma$. Subsequently, the DCs residing in the tumor restimulate the antigen-specific CTLs, which recognize and kill the tumor cells carrying the antigen. AspH, aspartate $\beta$-hydroxylase; Ag, antigen; DC, dendritic cell; CTL, cytotoxic lymphocyte.

liver cancer worldwide in 2019 (54). Although therapeutic efforts have improved over the last few decades, the mortality rate of HCC has increased by 2.8 and $3.4 \%$ per year in men and women, respectively (55). Therefore, there is an urgent need for new treatment methods and a deeper understanding of HCC. The relevance of AspH modification in HCC has been extensively studied, and several studies have revealed that AspH is highly expressed in HCC and is associated with cell proliferation, invasion and malignant transformation $(1,11,31,56-58)$. AspH binding to GSK $3 \beta$ inhibits its phosphorylation and inactivation, and blocks the interactions with the upstream kinases AKT and p38 (47). Inhibition of AspH enzymatic activity promotes HCC cell senescence and therefore delays tumor progression by increasing the phosphorylation of GSK3 $\beta$ and p16 expression (Fig. 2B) (47). Additionally, a previous study has revealed that AspH promotes cell proliferation by upregulating cyclin D1 and c-Myc expression (59). MicroRNA (miR)-200a, an upstream target gene of AspH that is rarely detected in liver tumor tissues and cell lines, suppresses cyclin D1 and c-Myc expression by downregulating AspH expression (59). Another study has revealed that AspH expression can be upregulated by insulin and IGF-1 in HCC (45). Insulin and IGF-1 stimulated AspH expression by increasing the phosphorylation of MAPK, ERK and AKT to enhance cell motility and invasiveness (45). Malignant phenotypes, such as tumor cell proliferation, migration, invasion and metastasis of HCC, are partially due to the activation of insulin and IGF-1, which increases AspH expression and subsequently activates the Notch signaling cascade $(23,30,31)$. In addition, in HCC cells treated with an SMI (MO-I-1100) of $\beta$-hydroxylase, the activation of Notch signaling was inhibited, and the abilities of cell migration, invasion and metastasis were decreased compared with in untreated counterparts (23). Decreased copy number and dysfunction of mitochondrial DNA (mtDNA) are associated with the malignant phenotypes of HCC (60). AspH upregulation can destroy the integrity of mtDNA by blocking histone $\mathrm{H} 2 \mathrm{~A}$ member X-mitochondrial transcription factor A signaling, resulting in abnormal mitochondrial membrane potential, decreased ATP generation and increased reactive oxygen species; however, these effects can be reversed using small interfering RNAs against AspH (60). AspH is distributed on the surface of tumor cells, which makes it a target for immunotherapy. AspH-loaded DCs inoculated into HCC tumor-bearing mice can significantly suppress tumor growth, prolong survival and delay recurrence following surgical resection (52). Furthermore, both in healthy donors and patients with HCC, compared with $\alpha$-fetoprotein-loaded DCs, AspH-loaded DCs can stimulate the activation of antigen-specific $\mathrm{CD} 4^{+} \mathrm{T}$ cells and $\mathrm{CD} 8{ }^{+} \mathrm{CTLs}$, which are important to initiate antitumor immune responses (61-63).

AspH in cholangiocarcinoma (CC). CC accounted for 10-25\% of primary liver tumors globally in 2011, with a poor prognosis due to a lack of early diagnosis and effective treatment $(64,65)$. It has been demonstrated that AspH is highly expressed in $\mathrm{CC}$, while $\mathrm{AspH}$ upregulation is not observed in normal tissues, non-neoplastic epithelial cells and stromal cells (1). Clinicopathologically, AspH upregulation promotes CC invasion, metastasis and poor prognosis (66). Northern blotting suggests that $\mathrm{AspH}$ expression is upregulated in $\mathrm{CC}$ to promote intrahepatic spread and metastasis, since the $\mathrm{AspH}$ protein enhances the sarcomatous change and epithelial-mesenchymal 
transition (EMT) of CC (67). Additionally, the activation of the Notch signaling pathway was detected in CC; furthermore, enhanced Notch signaling and upregulation of downstream target genes (such as HEY1 and HES1) were observed when wild-type (wt)-AspH was transfected into HEK293 cells (68). As a cycle regulatory protein, cyclin D1 upregulation is closely associated with the progression and prognosis of CC (69). Knocking down AspH significantly downregulated cyclin D1 expression; however, overexpression of Notch partially rescued cyclin D1 levels, suggesting that AspH promotes CC cell proliferation through Notch-mediated cyclin D1 expression (68). In addition, in in vitro experiments, AspH-loaded DCs recruited $\mathrm{CD}^{+}$lymphocytes in tumor tissues to inhibit intrahepatic CC development and metastasis (70). In a CC model, a large portion of BDEneu-C24 cells expressed the AspH protein, causing a concentrated collagen matrix reaction during tumor formation; however, $\mathrm{CD}^{+} \mathrm{T}$ cells can penetrate the matrix barrier and reduce or delay the growth of CC (70). Recently, it has been reported that AspH promotes the growth and progression of $\mathrm{CC}$ by regulating the phosphorylation (and therefore inactivation) of RB1 (71). As a cancer suppressor gene, RB1 serves a vital role in cell cycle progression from $\mathrm{G}_{0} / \mathrm{G}_{1}$ to $\mathrm{S}$ phase and cell senescence $(72,73)$. AspH upregulation increases the protein-protein interaction between RB1 and cell cycle-associated proteins, which in turn results in enhanced phosphorylation of RB1 (71). In addition, this interaction can be suppressed by inhibitors of hydroxylase activity (71).

AspH in pancreatic carcinoma $(P C)$. PC was the third leading cause of cancer-associated mortality in the USA in 2019 , with the lowest 5-year relative survival rate $(9 \%)$ among all other types of cancer (74). The $\beta$-hydroxylase activity of AspH was proven to boost the malignant phenotypes of PC cells, such as cell migration, 2D and 3D invasion, EMT, ECM degradation/remodeling, stemness, microsphere formation and metastasis; these phenotypes were specifically suppressed using an SMI (MO-I-1182) (75). Additionally, it has been revealed that in a patient-derived xenograft (PDX) murine model with spontaneous pulmonary metastasis of human pancreatic ductal adenocarcinoma (PDAC), AspH promotes primary tumor development and pulmonary metastasis; these harmful effects can also be blocked using an SMI (MO-I-1182) (76). On the other hand, the proto-oncogene SRC can be activated by $\mathrm{AspH}$ through direct interaction with ADAM12/15 (75). Furthermore, the highly expressed $\mathrm{AspH}-\mathrm{SRC}$ axis is a marker of poor prognosis in PC due to angiogenesis, invadopodia formation and metastasis $(75,77)$. AspH can promote PC growth by activating Notch signaling cascades $(29,78)$. Mechanistically, the ECD of Notch receptors contains 36 consecutive EGF-like repeats for the $\beta$-hydroxylation of aspartate/asparagine $(27,29)$. AspH directly stimulates Notch to upregulate downstream responsive target genes, including HES1 and HEY1 (29). In AspH-overexpressing PDAC cell lines, a human monoclonal antibody against AspH (SNS-622-DM1) exerts significant antitumor effects by facilitating tumor cell $\mathrm{G}_{2} / \mathrm{M}$ phase accumulation and increasing cellular cleaved caspase 3 expression (79). Additionally, SNS-622-DM1 can inhibit tumor growth and pulmonary metastasis in a PDX murine model (79).
AspH in colorectal carcinoma (CRC). CRC is the fourth most deadly cancer, with $\sim 900,000$ deaths annually worldwide in 2019 (80). A bioinformatics analysis revealed that the mRNA and protein levels of AspH are upregulated in CRC compared with in normal tissues due to gene copy number variations and promoter demethylation (81). AspH accumulates at the invasive tumor margin, which may be associated with cell invasion and infiltration (81). It has been recently reported that Notch signaling recruits TGF $\beta$-dependent neutrophils to drive CRC metastasis; this pathway has an important role in the tumor microenvironment and predicts a poor survival in patients with CRC (82). Notably, knocking down AspH or using specific SMIs (MO-I-1144) decreases Notch expression in CRC, inhibiting tumor development and metastasis (81).

AspH in breast carcinoma. Studies have revealed the presence of $\mathrm{AspH}$ gene amplification in invasive/advanced ductal carcinoma and $\mathrm{AspH}$ silencing in normal adult breast tissues $(32,83)$. AspH upregulation activates the Notch signaling pathway, increases the synthesis/release of pro-oncogenic exosomes and subsequently enhances EMT, 2D and 3D invasion, stemness, angiogenesis and metastases in breast cancer; these malignant phenotypes are reversed using an SMI (MO-I-1182) (32). AspH stimulates the Notch cascade by directly interacting with Notch receptors, ligands (JAGs) or ADAM10/17 modulators (32). The AspH-Notch axis is essential for the progression and prognosis of breast cancer (32). In mouse models, high levels of AspH induced more aggressive tumors, characterized by rapid growth and extensive metastases (32). Notably, phage vaccination markedly decreased pulmonary metastasis and enhanced survival in the 4T1 breast cancer model (with AspH overexpression) (53). On the other hand, in estrogen receptor-positive breast cancer cells, the activation of MAPK and PI3K cascades upregulates AspH mRNA expression when tamoxifen sensitivity is decreased (84). Furthermore, upregulated AspH expression decreases the progression-free survival of patients with luminal B breast cancer who received adjuvant endocrine therapy (84). Therefore, endocrine sensitivity of endocrine-resistant breast cancer with high AspH expression may be restored by blocking the MAPK and PI3K signaling pathways (84).

AspH in glioblastoma (GBM). GBM was the most common primary malignant brain tumor among adults worldwide in 2016 (85). Via analyzing whole genome alternative splicing events in 498 GBM cases, it was revealed that AspH expression is upregulated in GBM and is associated with the onset and progression of cancer (86). A previous study has demonstrated that protein levels of $\mathrm{AspH}$ and of the proliferation-associated protein Ki-67 are upregulated in more aggressive GBM cases compared with well differentiated cases (87). Furthermore, AspH knockdown or SMI (MO-I-1100, MO-I-400, MO-I-500 and MO-I-1151) treatment targeting hydroxylase activity decreases the viability and directional motility of GBM cells (87). Moreover, shorter progression-free survival and overall survival are associated with $\mathrm{AspH}$ upregulation and HIF-1 $\alpha$ expression in patients with GBM, analyzed using immunohistochemistry (87). The Cancer Genome Atlas gene database revealed that AspH and HIF-1 $\alpha$ were significantly upregulated in the mesenchymal subtype of GBM (87). This 
Table I. Diverse molecular functions of aspartate $\beta$-hydroxylase in cancer.

\begin{tabular}{|c|c|c|c|c|}
\hline First author, year & Cancer type & Mechanisms & Molecular targets & (Refs.) \\
\hline $\begin{array}{l}\text { Cantarini et al, 2006; } \\
\text { Chung et al, } 2016\end{array}$ & Hepatocellular carcinoma & $\begin{array}{l}\text { Activating Notch signaling } \\
\text { pathway }\end{array}$ & Notch receptors and ligands & $(30,31)$ \\
\hline Iwagami et al, 2016 & & Delaying cell senescence & $\begin{array}{l}\text { Inhibition of GSK3} \beta \\
\text { phosphorylation }\end{array}$ & $(47)$ \\
\hline Tang et al, 2017 & & $\begin{array}{l}\text { Destroying mitochondria } \\
\text { integrity }\end{array}$ & $\begin{array}{l}\text { Decrease of the interaction } \\
\text { between histone } \mathrm{H} 2 \mathrm{~A} \text { member } \mathrm{X} \\
\text { and mitochondrial transcription } \\
\text { factor A }\end{array}$ & $(60)$ \\
\hline Yoo et al, 2009 & Cholangiocarcinoma & $\begin{array}{l}\text { Enhancing sarcomatous change } \\
\text { and epithelial-mesenchymal } \\
\text { transition }\end{array}$ & Unknown & $(67)$ \\
\hline $\begin{array}{l}\text { Huang et al, 2016; } \\
\text { Sugimachi et al, } 2001\end{array}$ & & $\begin{array}{l}\text { Activating Notch signaling } \\
\text { pathway }\end{array}$ & Notch receptors and ligands & $(68,69)$ \\
\hline Huang et al, 2018 & & $\begin{array}{l}\text { Delaying cell growth and } \\
\text { senescence }\end{array}$ & $\begin{array}{l}\text { Enhancement of RB1 } \\
\text { phosphorylation }\end{array}$ & (71) \\
\hline $\begin{array}{l}\text { Jove and Hanafusa, } \\
1987\end{array}$ & Pancreatic carcinoma & $\begin{array}{l}\text { Activating SRC signaling } \\
\text { pathway }\end{array}$ & $\begin{array}{l}\text { Interaction with } \\
\text { ADAM12/ADAM15 }\end{array}$ & (77) \\
\hline Dong et al, 2015 & & $\begin{array}{l}\text { Activating Notch signaling } \\
\text { pathway }\end{array}$ & Notch receptors and ligands & (29) \\
\hline Benelli et al, 2020 & Colorectal carcinoma & $\begin{array}{l}\text { Activating Notch signaling } \\
\text { pathway }\end{array}$ & Notch receptors and ligands & $(81)$ \\
\hline Lin et al, 2019 & Breast carcinoma & $\begin{array}{l}\text { Activating Notch signaling } \\
\text { pathway }\end{array}$ & Notch receptors and ligands & $(32)$ \\
\hline Shimoda et al, 2017 & & $\begin{array}{l}\text { Decreasing endocrine } \\
\text { sensitivity }\end{array}$ & Unknown & $(84)$ \\
\hline Sturla et al, 2016 & Glioblastoma & Increasing cell proliferation & Upregulation of $\mathrm{Ki}-67$ protein & $(87)$ \\
\hline Chen et al, 2019 & Endometrial carcinoma & $\begin{array}{l}\text { Increasing cell proliferation } \\
\text { and migration }\end{array}$ & Unknown & $(88)$ \\
\hline Sepe et al, 2002 & Neuroblastoma & Increasing cell motility & $\mathrm{p} 21 / \mathrm{Waf} 1$ and $\mathrm{p} 16$ & $(90)$ \\
\hline Luu et al, 2009 & Non-small cell lung cancer & $\begin{array}{l}\text { Increasing invasiveness and } \\
\text { metastatic }\end{array}$ & Unknown & $(91)$ \\
\hline Lee, 2008 & Gastric carcinoma & $\begin{array}{l}\text { Promoting growth and } \\
\text { migration }\end{array}$ & Unknown & $(92)$ \\
\hline
\end{tabular}

demonstrates that both AspH and HIF-1 $\alpha$ may be involved in mesenchymal transformation and may subsequently induce aggressive and invasive phenotypes (87).

AspH in other types of cancer. Similarly to the aforementioned types of cancer, modulation of $\mathrm{AspH}$ function serves a critical role in endometrial cancer (EC), neuroblastoma, non-small cell lung carcinoma (NSCLC) and gastric cancer (88-92). Compared with normal cell lines, AspH expression was upregulated in EC cell lines, while miR-135a expression was downregulated (88). Cell Counting Kit-8 and wound-healing assays revealed that cell proliferation and migration were decreased by miR-135a overexpression. Conversely, high levels of AspH led to increased cell proliferation and migration, and miR-135a overexpression decreased the luciferase activity of EC cells transfected with wt-AspH 3'-untranslated region (UTR) but not mutant-AspH 3'-UTR (88). AspH upregulation restored the inhibitory effects of miR-135a on EC cells (88). These observations suggest that miR-135a affects EC growth and invasion by regulating AspH levels (88). AspH expression was significantly increased in neuroblastoma cells compared with in CNS-derived primitive neuroectodermal tumor cells. Mechanistically, insulin and IGF-1 increased directional motility by inducing AspH expression (89). However, treatment with AKT, ERK or cyclin-dependent kinase 5 (CDK-5) inhibitors significantly decreased insulin- and IGF-1-stimulated AspH mRNA expression and motility (89). These results suggest that ERK, AKT and CDK-5 signaling may mediate insulin and IGF-1 regulation of AspH at the level of transcription (89). In addition, high expression levels of AspH 
significantly enhanced neuroblastoma Sy5y cell motility, while the inhibition of AspH by antisense oligodeoxynucleotides decreased the motility of Sy5y cells and enhanced the expression levels of $\mathrm{p} 21 / \mathrm{Waf} 1$ and $\mathrm{p} 16$, indicating that $\mathrm{AspH}$ is involved in tumor invasion and metastasis (90). In NSCLC, FB50 immunohistochemical staining revealed a marked increase in AspH expression, particularly in squamous cell carcinoma (91). High levels of AspH immunoreactivity are associated with poor survival and prognosis in patients with NSCLC, and AspH upregulation may increase the potential for tumor invasiveness and metastatic spread due to alterations in cell shape and adhesion (91). Finally, as a truncated isoform of $\mathrm{AspH}$, humbug expression has been reported to be upregulated in several gastric cancer cell lines, especially in highly aggressive cells (92). High expression levels of humbug increased the anchorage-independent cell proliferation capability according to a colony formation assay; additionally, Transwell migration assays revealed that overexpression of humbug can promote cell migration and invasion compared with control vector-transfected cells (92). Therefore, humbug may be a molecule that affects the development and progression of gastric cancer (92).

\section{Conclusion and outlook}

An increasing number of studies have revealed that AspH expression is upregulated in several types of human tumor. Its hydroxylase activity serves an essential role in promoting malignant tumor phenotypes, including growth, proliferation, invasion and metastasis. The present review discussed multiple key signaling pathways and mechanisms underlying the function of AspH in cancer. Notably, AspH activates Notch and PI3K-dependent signaling pathways, delays tumor cell senescence, destroys the integrity of mitochondria and subsequently leads to tumor development and a poor prognosis (Table I). Therefore, different specific and selective SMIs targeting hydroxylase activity have been designed and have revealed promising results in vitro and in vivo. Additionally, the versatile function of AspH in the immune system has been investigated over the last decade. Phage vaccination and DCs fused to the AspH protein yield substantial antitumor effects in animal models. These studies indicate that $\mathrm{AspH}$ may become a novel prognostic marker and an immunotarget for antitumor agents. Although there has been some progress with respect to the role of AspH in tumor development, further investigations are required to improve the efficacy of cancer treatment and provide additional benefits to clinical patients.

\section{Acknowledgements}

Not applicable.

\section{Funding}

The present review was supported by a grant from the National Natural Science Foundation of China (grant no. 81272681).

\section{Availability of data and materials}

Not applicable.

\section{Authors' contributions}

$\mathrm{HZ}$ and $\mathrm{WZ}$ designed the study. WZ and $\mathrm{XW}$ wrote the manuscript. JH prepared the figures. BB reviewed and edited the manuscript. All authors read and approved the final manuscript and agree to be accountable for all aspects of the research.

\section{Ethics approval and consent to participate}

Not applicable.

\section{Patient consent for publication}

Not applicable.

\section{Competing interests}

The authors declare that they have no competing interests.

\section{References}

1. Lavaissiere L, Jia S, Nishiyama M, De La Monte S, Stern AM, Wands JR and Friedman PA: Overexpression of human aspartyl(asparaginyl)beta-hydroxylase in hepatocellular carcinoma and cholangiocarcinoma. J Clin Invest 98: 1313-1323, 1996.

2. Korioth F, Gieffers C and Frey J: Cloning and characterization of the human gene encoding aspartyl beta-hydroxylase. Gene 150: 395-399, 1994.

3. Dinchuk JE, Henderson NL, Burn TC, Huber R, Ho SP, Link J, O'Neil KT, Focht RJ, Scully MS, Hollis JM, et al: Aspartyl beta-hydroxylase (Asph) and an evolutionarily conserved isoform of Asph missing the catalytic domain share exons with junctin. J Biol Chem 275: 39543-39554, 2000.

4. Wang Q, VanDusen WJ, Petroski CJ, Garsky VM, Stern AM and Friedman PA: Bovine liver aspartyl beta-hydroxylase: Purification and characterization. J Biol Chem 266: 14004-14010, 1991.

5. McGinnis K, Ku GM, VanDusen WJ, Fu J, Garsky V, Stern AM and Friedman PA: Site-directed mutagenesis of residues in a conserved region of bovine aspartyl (asparaginyl) beta-hydroxylase: Evidence that histidine 675 has a role in binding $\mathrm{Fe} 2+$. Biochemistry 35: 3957-3962, 1996.

6. Stenflo J, Holme E, Lindstedt S, Chandramouli N, Huang LH, Tam JP and Merrifield RB: Hydroxylation of aspartic acid in domains homologous to the epidermal growth factor precursor is catalyzed by a 2-oxoglutarate-dependent dioxygenase. Proc Natl Acad Sci USA 86: 444-447, 1989.

7. Pfeffer I, Brewitz L, Krojer T, Jensen SA, Kochan GT, Kershaw NJ, Hewitson KS, McNeill LA, Kramer H, Münzel M, et al: Aspartate/asparagine- $\beta$-hydroxylase crystal structures reveal an unexpected epidermal growth factor-like domain substrate disulfide pattern. Nat Commun 10: 4910, 2019.

8. Gronke RS, VanDusen WJ, Garsky VM, Jacobs JW, Sardana MK, Stern AM and Friedman PA: Aspartyl beta-hydroxylase: In vitro hydroxylation of a synthetic peptide based on the structure of the first growth factor-like domain of human factor IX. Proc Natl Acad Sci USA 86: 3609-3613, 1989.

9. Jia S, VanDusen WJ, Diehl RE, Kohl NE, Dixon RA, Elliston KO, Stern AM and Friedman PA: cDNA cloning and expression of bovine aspartyl (asparaginyl) beta-hydroxylase. J Biol Chem 267: 14322-14327, 1992.

10. Treves S, Feriotto G, Moccagatta L, Gambari R and Zorzato F: Molecular cloning, expression, functional characterization, chromosomal localization, and gene structure of junctate, a novel integral calcium binding protein of sarco(endo)plasmic reticulum membrane. J Biol Chem 275: 39555-39568, 2000.

11. Bruix J and Llovet JM: Prognostic prediction and treatment strategy in hepatocellular carcinoma. Hepatology 35: 519-524, 2002.

12. Hong CS, Kwon SJ and Kim DH: Multiple functions of junctin and junctate, two distinct isoforms of aspartyl beta-hydroxylase. Biochem Biophys Res Commun 362: 1-4, 2007. 
13. Jones LR, Zhang L, Sanborn K, Jorgensen AO and Kelley J: Purification, primary structure, and immunological characterization of the $26-\mathrm{kDa}$ calsequestrin binding protein (junctin) from cardiac junctional sarcoplasmic reticulum. J Biol Chem 270: 30787-30796, 1995.

14. Siggs OM, Souzeau E and Craig JE: Loss of ciliary zonule protein hydroxylation and lens stability as a predicted consequence of biallelic ASPH variation. Ophthalmic Genet 40: 12-16, 2019.

15. Abarca Barriga $\mathrm{HH}$, Caballero $\mathrm{N}$, Trubnykova $\mathrm{M}$, Castro-Mujica MDC, La Serna-Infantes JE, Vásquez F and Hennekam RC: A novel ASPH variant extends the phenotype of Shawaf-Traboulsi syndrome. Am J Med Genet Part A 176: 2494-2500, 2018.

16. Kulkarni N, Lloyd IC, Ashworth J, Biswas S, Black GCM and Clayton-Smith J; NIHR BioResource Consortium: Trabouls syndrome due to ASPH mutation: An under-recognised cause of ectopia lentis. Clin Dysmorphol 28: 184-189, 2019.

17. Patel N, Khan AO, Mansour A, Mohamed JY, Al-Assiri A, Haddad R, Jia X, Xiong Y, Mégarbané A, Traboulsi EI and Alkuraya FS: Mutations in ASPH cause facial dysmorphism, lens dislocation, anterior-segment abnormalities, and spontaneous filtering blebs, or Traboulsi syndrome. Am J Hum Genet 94: 755-759, 2014.

18. Dinchuk JE, Focht RJ, Kelley JA, Henderson NL, Zolotarjova NI, Wynn R, Neff NT, Link J, Huber RM, Burn TC, et al: Absence of post-translational aspartyl beta-hydroxylation of epidermal growth factor domains in mice leads to developmental defects and an increased incidence of intestinal neoplasia. J Biol Chem 277: 12970-12977, 2002.

19. Gundogan F, Elwood G, Greco D, Rubin LP, Pinar H, Carlson RI, Wands JR and de la Monte SM: Role of aspartyl-(asparaginyl) beta-hydroxylase in placental implantation: Relevance to early pregnancy loss. Hum Pathol 38: 50-59, 2007.

20. Yang H, Song K, Xue T, Xue XP, Huyan T, Wang W and Wang H: The distribution and expression profiles of human aspartyl/asparaginyl beta-hydroxylase in tumor cell lines and human tissues. Oncol Rep 24: 1257-1264, 2010.

21. Ince N, de La Monte SM and Wands JR: Overexpression of human aspartyl (asparaginyl) beta-hydroxylase is associated with malignant transformation. Cancer Res 60: 1261-1266, 2000.

22. Zou Q, Hou Y, Wang H, Wang K, Xing X, Xia Y, Wan X, Li J, Jiao B Liu J, et al: Hydroxylase activity of ASPH promotes hepatocellular carcinoma metastasis through epithelial-to-mesenchymal transition pathway. EBioMedicine 31: 287-298, 2018.

23. Aihara A, Huang CK, Olsen MJ, Lin Q, Chung W, Tang Q, Dong $X$ and Wands JR: A cell-surface $\beta$-hydroxylase is a biomarker and therapeutic target for hepatocellular carcinoma. Hepatology 60: 1302-1313, 2014.

24. Artavanis-Tsakonas S, Rand MD and Lake RJ: Notch signaling: Cell fate control and signal integration in development. Science 284: 770-776, 1999.

25. Avila JL and Kissil JL: Notch signaling in pancreatic cancer: Oncogene or tumor suppressor? Trends Mol Med 19: 320-327, 2013.

26. Wang H, Zang C, Liu XS and Aster JC: The role of notch receptors in transcriptional regulation. J Cell Physiol 230: 982-988, 2015.

27. Wharton KA, Johansen KM, Xu T and Artavanis-Tsakonas S: Nucleotide sequence from the neurogenic locus Notch implies a gene product that shares homology with proteins containing EGF-like repeats. Cell 43: 567-581, 1985.

28. Penton AL, Leonard LD and Spinner NB: Notch signaling in human development and disease. Semin Cell Dev Biol 23: 450-457, 2012

29. Dong X, Lin Q, Aihara A, Li Y, Huang CK, Chung W, Tang Q, Chen X, Carlson R, Nadolny C, et al: Aspartate $\beta$-hydroxylase expression promotes a malignant pancreatic cellular phenotype. Oncotarget 6: 1231-1248, 2015.

30. Cantarini MC, de La Monte SM, Pang M, Tong M, D'Errico A, Trevisani F and Wands JR: Aspartyl-asparagyl beta hydroxylase over-expression in human hepatoma is linked to activation of insulin-like growth factor and Notch signaling mechanisms. Hepatology 44: 446-457, 2006.

31. Chung W, Kim M, de la Monte S, Longato L, Carlson R, Slagle BL, Dong X and Wands JR: Activation of signal transduction pathways during hepatic oncogenesis. Cancer Lett 370: 1-9, 2016.

32. Lin Q, Chen X, Meng F, Ogawa K, Li M, Song R, Zhang S, Zhang Z, Kong X, Xu Q, et al: ASPH-notch axis guided exosomal delivery of prometastatic secretome renders breast cancer multi-organ metastasis. Mol Cancer 18: 156, 2019.
33. Boelens MC, Wu TJ, Nabet BY, Xu B, Qiu Y, Yoon T, Azzam DJ, Twyman-Saint Victor C, Wiemann BZ, Ishwaran $\mathrm{H}$, et al: Exosome transfer from stromal to breast cancer cells regulates therapy resistance pathways. Cell 159: 499-513, 2014.

34. Luga V, Zhang L, Viloria-Petit AM, Ogunjimi AA, Inanlou MR, Chiu E, Buchanan M,Hosein AN, Basik M and Wrana JL: Exosomes mediate stromal mobilization of autocrine Wnt-PCP signaling in breast cancer cell migration. Cell 151: 1542-1556, 2012.

35. Vaupel P, Mayer A and Höckel M: Tumor hypoxia and malignant progression. Methods Enzymol 381: 335-354, 2004.

36. Chen J, Imanaka N, Chen J and Griffin JD: Hypoxia potentiates Notch signaling in breast cancer leading to decreased E-cadherin expression and increased cell migration and invasion. $\mathrm{Br} \mathrm{J}$ Cancer 102: 351-360, 2010.

37. Lawton M, Tong M, Gundogan F, Wands JR and de La Monte SM: Aspartyl-(asparaginyl) beta-hydroxylase, hypoxia-inducible factor-alpha and Notch cross-talk in regulating neuronal motility. Oxid Med Cell Longev 3: 347-356, 2010.

38. Sivasankaran B, Degen M, Ghaffari A, Hegi ME, Hamou MF, Ionescu MC,Zweifel C, Tolnay M, Wasner M, Mergenthaler S, et al: Tenascin-C is a novel RBPJkappa-induced target gene for Notch signaling in gliomas. Cancer Res 69: 458-465, 2009.

39. Wagner EF and Nebreda ÁR: Signal integration by JNK and p38 MAPK pathways in cancer development. Nat Rev Cancer 9: 537-549, 2009.

40. Thorpe LM, Yuzugullu H and Zhao JJ: PI3K in cancer: Divergent roles of isoforms, modes of activation and therapeutic targeting. Nat Rev Cancer 15: 7-24, 2015.

41. Engelman JA, Luo J and Cantley LC: The evolution of phosphatidylinositol 3-kinases as regulators of growth and metabolism. Nat Rev Genet 7: 606-619, 2006.

42. Giorgetti S, Ballotti R, Kowalski-Chauvel A, Tartare S and Van Obberghen E: The insulin and insulin-like growth factor-I receptor substrate IRS-1 associates with and activates phosphatidylinositol 3-kinase in vitro. J Biol Chem 268: 7358-7364, 1993.

43. Hermanto U, Zong CS and Wang LH: Inhibition of mitogen-activated protein kinase kinase selectively inhibits cell proliferation in human breast cancer cells displaying enhanced insulin-like growth factor I-mediated mitogen-activated protein kinase activation. Cell Growth Differ 11: 655-664, 2000.

44. Vuori K and Ruoslahti E: Association of insulin receptor substrate-1 with integrins. Science 266: 1576-1578, 1994.

45. de la Monte SM, Tamaki S, Cantarini MC, Ince N, Wiedmann M, Carter JJ, Lahousse SA, Califano S, Maeda T, Ueno T, et al: Aspartyl-(asparaginyl)-beta-hydroxylase regulates hepatocellular carcinoma invasiveness. J Hepatol 44: 971-983, 2006.

46. Ngeow KC, Friedrichsen HJ, Li L, Zeng Z, Andrews S, Volpon L, Brunsdon H, Berridge G, Picaud S, Fischer R, et al: BRAF/MAPK and GSK3 signaling converges to control MITF nuclear export. Proc Natl Acad Sci USA 115: E8668-E8677, 2018.

47. Iwagami Y, Huang CK, Olsen MJ, Thomas JM, Jang G, Kim M, Lin Q, Carlson RI, Wagner CE, Dong X and Wands JR: Aspartate $\beta$-hydroxylase modulates cellular senescence through glycogen synthase kinase $3 \beta$ in hepatocellular carcinoma. Hepatology 63 : 1213-1226, 2016

48. Sharma P and Allison JP: The future of immune checkpoint therapy. Science 348: 56-61, 2015.

49. Chen DS and Mellman I: Elements of cancer immunity and the cancer-immune set point. Nature 541: 321-330, 2017.

50. Mu CY, Huang JA, Chen Y, Chen C and Zhang XG: High expression of PD-L1 in lung cancer may contribute to poor prognosis and tumor cells immune escape through suppressing tumor infiltrating dendritic cells maturation. Med Oncol 28: 682-688, 2011.

51. Borst J, Ahrends T, Bąbała N, Melief CJM and Kastenmüller W: CD4+ T cell help in cancer immunology and immunotherapy. Nat Rev Immunol 18: 635-647, 2018.

52. Tomimaru Y, Mishra S, Safran H, Charpentier KP, Martin W, DeGroot AS, Gregory SHand WandsJR: Aspartate- $\beta$-hydroxylase induces epitope-specific $\mathrm{T}$ cell responses in hepatocellular carcinoma. Vaccine 33: 1256-1266, 2015.

53. Iwagami Y, Casulli S, Nagaoka K, Kim M, Carlson RI, Ogawa K, Lebowitz MS, Fuller S, Biswas B, Stewart S, et al: Lambda phage-based vaccine induces antitumor immunity in hepatocellular carcinoma. Heliyon 3: e00407, 2017.

54. Petrick JL and McGlynn KA: The changing epidemiology of primary liver cancer. Curr Epidemiol Reports 6: 104-111, 2019.

55. Ryerson AB, Eheman CR, Altekruse SF, Ward JW, Jemal A, Sherman RL, Henley SJ, Holtzman D, Lake A, Noone AM, et al: Annual report to the nation on the status of cancer, 1975-2012, featuring the increasing incidence of liver cancer. Cancer 122: 1312-1337, 2016. 
56. Tomimaru Y, Koga H, Yano H, de la Monte S, Wands JR and Kim M: Upregulation of T-cell factor-4 isoform-responsive target genes in hepatocellular carcinoma. Liver Int 33 : 1100-1112., 2013.

57. Wang K, Liu J, Yan ZL, Li J, Shi LH, Cong WM, Xia Y, Zou QF, $\mathrm{Xi}$ T, Shen F, et al: Overexpression of aspartyl-(asparaginyl)- $\beta$ hydroxylase in hepatocellular carcinoma is associated with worse surgical outcome. Hepatology 52: 164-173, 2010.

58. Xue T, Su J, Li H and Xue X: Evaluation of HAAH/humbug quantitative detection in the diagnosis of hepatocellular carcinoma. Oncol Rep 33: 329-337, 2015.

59. Yao WF, Liu JW and Huang DS: Mir-200a inhibits cell proliferation and EMT by down-regulating the ASPH expression levels and affecting ERK and PI3K/Akt pathways in human hepatoma cells. Am J Transl Res 10: 1117-1130, 2018.

60. Tang C, Hou Y, Wang H, Wang K, Xiang H, Wan X, Xia Y, Li J, Wei W, Xu S, et al: Aspartate $\beta$-hydroxylase disrupts mitochondrial DNA stability and function in hepatocellular carcinoma. Oncogenesis 6: e362, 2017.

61. Shimoda M, Tomimaru Y, Charpentier KP, Safran H, Carlson RI and Wands J: Tumor progression-related transmembrane protein aspartate- $\beta$-hydroxylase is a target for immunotherapy of hepatocellular carcinoma. J Hepatol 56: 1129-1135, 2012.

62. Marzo AL, Kinnear BF, Lake RA, Frelinger JJ, Collins EJ, Robinson BW and Scott B: Tumor-specific CD4 + T cells have a major 'post-licensing' role in CTL mediated anti-tumor immunity. J Immunol 165: 6047-6055, 2000.

63. Kennedy R and Celis E: Multiple roles for CD4+ T cells in anti-tumor immune responses. Immunol Rev 222: 129-144, 2008

64. Tyson GL and El-Serag HB: Risk factors for cholangiocarcinoma. Hepatology 54: 173-184, 2011.

65. Weber SM, Jarnagin WR, Klimstra D, DeMatteo RP, Fong Y and Blumgart LH: Intrahepatic cholangiocarcinoma: Resectability, recurrence pattern, and outcomes. J Am Coll Surg 193: 384-391, 2001.

66. Maeda T, Taguchi K, Aishima S, Shimada M, Hintz D, Larusso N, Gores G, Tsuneyoshi M, Sugimachi K, Wands JR and de la Monte SM: Clinicopathological correlates of aspartyl (asparaginyl) beta-hydroxylase over-expression in cholangiocarcinoma. Cancer Detect Prev 28: 313-318, 2004

67. Yoo HJ, Yun BR, Kwon JH, Ahn HS, Seol MA, Lee MJ, Yu GR, Yu HC, Hong B, Choi K and Kim DG: Genetic and expression alterations in association with the sarcomatous change of cholangiocarcinoma cells. Exp Mol Med 41: 102-115, 2009.

68. Huang CK, Iwagami Y, Aihara A, Chung W, de la Monte S, Thomas JM, Olsen M, Carlson R, Yu T, Dong X and Wands J: Anti-tumor effects of second generation $\beta$-hydroxylase inhibitors on cholangiocarcinoma development and progression. PLoS One 11: e0150336, 2016.

69. Sugimachi K, Aishima S, Taguchi K, Tanaka S, Shimada M, Kajiyama K, Sugimachi K and Tsuneyoshi M: The role of overexpression and gene amplification of cyclin D1 in intrahepatic cholangiocarcinoma. J Hepatol 35: 74-79, 2001.

70. Noda T, Shimoda M, Ortiz V, Sirica AE and Wands JR Immunization with aspartate- $\beta$-hydroxylase-loaded dendritic cells produces antitumor effects in a rat model of intrahepatic cholangiocarcinoma. Hepatology 55: 86-97, 2012.

71. Huang CK, Iwagami Y, Zou J, Casulli S, Lu S, Nagaoka K, Ji C, Ogawa K, Cao KY, Gao JS, et al: Aspartate beta-hydroxylase promotes cholangiocarcinoma progression by modulating RB1 phosphorylation. Cancer Lett 429: 1-10, 2018.

72. Giacinti $\mathrm{C}$ and Giordano A: RB and cell cycle progression Oncogene 25: 5220-5227, 2006.

73. Narita M, Nũnez S, Heard E, Narita M, Lin AW, Hearn SA, Spector DL, Hannon GJ and Lowe SW: Rb-mediated heterochromatin formation and silencing of E2F target genes during cellular senescence. Cell 113: 703-716, 2003.

74. Siegel RL, Miller KD and Jemal A: Cancer statistics, 2019. CA Cancer J Clin 69: 7-34, 2019.
75. Ogawa K, Lin Q, Li L, Bai X, Chen X, Chen H, Kong R, Wang Y, Zhu H, He F, et al: Aspartate $\beta$-hydroxylase promotes pancreatic ductal adenocarcinoma metastasis through activation of SRC signaling pathway. J Hematol Oncol 12: 144, 2019.

76. Ogawa K, Lin Q, Li L, Bai X, Chen X, Chen H, Kong R, Wang Y, $\mathrm{Zhu} \mathrm{H}, \mathrm{He} \mathrm{F}$, et al: Prometastatic secretome trafficking via exosomes initiates pancreatic cancer pulmonary metastasis. Cancer Lett 481: 63-75, 2020.

77. Jove $\mathrm{R}$ and Hanafusa $\mathrm{H}$ : Cell transformation by the viral sre oncogene. Annu Rev Cell Biol 3: 31-56, 1987.

78. Hou G, Xu B, Bi Y, Wu C, Ru B, Sun B and Bai X: Recent advances in research on aspartate $\beta$-hydroxylase (ASPH) in pancreatic cancer: A brief update. Bosn J Basic Med Sci 18: 297-304, 2018

79. NagaokaK, BaiX, OgawaK, Dong X,Zhang S,Zhou Y,Carlson RI, Jiang ZG, Fuller S, Lebowitz MS, et al: Anti-tumor activity of antibody drug conjugate targeting aspartate- $\beta$-hydroxylase in pancreatic ductal adenocarcinoma. Cancer Lett 449: 87-98, 2019.

80. Dekker E, Tanis PJ, Vleugels JLA, Kasi PM and Wallace MB: Colorectal cancer. Lancet 394: 1467-1480, 2019.

81. Benelli R, Costa D, Mastracci L, Grillo F, Olsen MJ, Barboro P, Poggi A and Ferrari N: Aspartate- $\beta$-hydroxylase: A promising target to limit the local invasiveness of colorectal cancer. Cancers (Basel) 12: 971, 2020

82. Jackstadt R, van Hooff SR, Leach JD, Cortes-Lavaud X, Lohuis JO, Ridgway RA, Wouters VM, Roper J, Kendall TJ, Roxburgh CS, et al: Epithelial NOTCH signaling rewires the tumor microenvironment of colorectal cancer to drive poor-prognosis subtypes and metastasis. Cancer Cell 36: 319-336.e7, 2019.

83. Kadota M, Sato M, Duncan B, Ooshima A, Yang HH, Diaz-Meyer N, Gere S, Kageyama S, Fukuoka J, Nagata T, et al: Identification of novel gene amplifications in breast cancer and coexistence of gene amplification with an activating mutation of PIK3CA. Cancer Res 69: 7357-7365, 2009.

84. Shimoda M, Hori A, Wands JR, Tsunashima R, Naoi Y, Miyake T, Tanei T, Kagara N, Shimazu K, Kim SJ and Noguchi S: Endocrine sensitivity of estrogen receptor-positive breast cancer is negatively correlated with aspartate- $\beta$-hydroxylase expression. Cancer Sci 108: 2454-2461, 2017.

85. Wirsching HG, Galanis E and Weller M: Glioblastoma. Handb Clin Neurol 134: 381-397, 2016

86. Chen X, Zhao C, Guo B, Zhao Z, Wang H and Fang Z: Systematic profiling of alternative mRNA splicing signature for predicting glioblastoma prognosis. Front Oncol 9: 928, 2019.

87. Sturla LM, Tong M, Hebda N, Gao J, Thomas JM, Olsen M and de la Monte SM: Aspartate- $\beta$-hydroxylase (ASPH): A potential therapeutic target in human malignant gliomas. Heliyon 2: e00203, 2016

88. Chen X, Jin P, Tang H and Zhang L: miR-135a acts as a tumor suppressor by targeting ASPH in endometrial cancer. Int J Clin Exp Pathol 12: 3384-3389, 2019.

89. Lahousse SA, Carter JJ, Xu XJ, Wands JR and de la Monte SM: Differential growth factor regulation of aspartyl-(asparaginyl)$\beta$-hydroxylase family genes in SH-Sy5y human neuroblastoma cells. BMC Cell Biol 7: 41, 2006.

90. Sepe PS, Lahousse SA, Gemelli B, Chang H, Maeda T, Wands JR and de la Monte SM: Role of the aspartyl-asparaginyl-beta-hydroxylase gene in neuroblastoma cell motility. Lab Invest 82: 881-891, 2002

91. Luu M, Sabo E, de la Monte SM, Greaves W, Wang J, Tavares R, Simao L, Wands JR, Resnick MB and Wang L: Prognostic value of aspartyl (asparaginyl)-beta-hydroxylase/humbug expression in non-small cell lung carcinoma. Hum Pathol 40: 639-644, 2009.

92. Lee JH: Overexpression of humbug promotes malignant progression in human gastric cancer cells. Oncol Rep 19: 795-800, 2008

This work is licensed under a Creative Commons Attribution-NonCommercial-NoDerivatives 4.0 International (CC BY-NC-ND 4.0) License. 